\title{
Ocular abnormalities in thin basement membrane disease
}

Deb Colville, Judy Savige, Pauline Branley, Diane Wilson

\begin{abstract}
Aim/background-Alport syndrome is an $X$ linked disease that results in renal failure, deafness, and ocular abnormalities including a dot and fleck retinopathy and anterior lenticonus. The ultrastructural appearance of the glomerular basement membrane in thin basement membrane disease (TBMD) resembles that seen in some patients with Alport syndrome, and in some cases this disease is inherited too. The aim of this study was to determine whether patients with TBMD have any ocular abnormalities.

Methods-The eyes of 17 unrelated individuals with TBMD were studied by slit-lamp, including biomicroscopic fundus examination with a $78 \mathrm{D}$ lens, by direct ophthalmoscopy, and by fundal photographs. The findings were compared with those in patients with IgA glomerulonephritis or Alport syndrome, and in normals.

Results-No patient with TBMD had a dot and fleck retinopathy or anterior lenticonus. A corneal dystrophy $(n=2)$ or pigmentation $(n=1)$, and retinal pigment epithelial clumping and maculopathy $(n=$ 1) were noted. Corneal, lens, and retinal dots were found in five $(\mathbf{2 9 \%})$, three $(\mathbf{1 8 \%})$, and $16(94 \%)$ patients, respectively, but these were also demonstrated in individuals with other renal diseases and in normal individuals.

Conclusions-The dot and fleck retinopathy and anterior lenticonus typical of Alport syndrome do not occur in TBMD. The protein abnormality and genetic defect in TBMD are not known, but the lack of ocular lesions suggests that the abnormal protein in this disease is more sparsely distributed or less important in the basement membranes of the eye than of the kidney. Alternatively, the protein may be less affected by the mutations responsible for TBMD.

(Br F Ophthalmol 1997;81:373-377)
\end{abstract}

Box Hill Hospital, Box

Hill, Victoria,

Australia

D Wilson

Correspondence to: Dr Judy Savige, University Department of Medicine, Austin and Repatriation Medical Centre, Heidelberg, Victoria 3084, Australia.

Accepted for publication 11 December 1997

Thin basement membrane disease (TBMD) is found in up to $10 \%$ of an otherwise healthy adult population. ${ }^{1}$ Affected individuals often present with microscopic haematuria, and sometimes with proteinuria and hypertension, ${ }^{2-4}$ but renal function is usually normal. In some patients, TBMD has been inherited $^{5}$ as an autosomal dominant condition, and the abnormal gene is not known but probably codes for a structural protein present in the glomerular and other basement membranes (GBM). ${ }^{6}$

Thinning of the GBM is also found in the biopsies of affected male children or carrier adult females with Alport syndrome. ${ }^{7}$ Alport syndrome is much less common than TBMD, and most patients demonstrate $\mathrm{X}$ linked inheritance. In this form mutations affect the gene for the $\alpha 5$ chain of type IV collagen, ${ }^{8}$ which is the major constituent of the GBM. Affected males present with haematuria by about the age of 6 years and have renal failure by the age of 20 years. ${ }^{9}{ }^{10}$ The basement membranes of the cochlea, cornea, lens capsule, and retina (Bruch's membrane) are also affected. ${ }^{11}{ }^{12}$ These result in a high tone sensorineural deafness, ${ }^{13}$ and a dot and fleck retinopathy and anterior lenticonus in more severely affected individuals. ${ }^{14-16}$ Many additional ocular abnormalities have been described, including corneal arcus, recurrent corneal epithelial erosions, corneal dystrophies (including posterior polymorphous corneal dystrophy), lens cataracts and dots, and corneal dots. ${ }^{17-19}$ Autosomal Alport syndrome accounts for about $15 \%$ of all patients with the condition, ${ }^{10}$ and mutations affect the $\alpha 3$ (IV) and $\alpha 4$ (IV) collagen chains. ${ }^{20}$ The renal and ocular manifestations are probably identical to those in $\mathrm{X}$ linked Alport syndrome.

The aim of this study was to determine whether patients with TBMD have any distinctive ocular features, in particular those that are found in Alport syndrome.

\section{Patients and methods}

THIN BASEMENT MEMBRANE DISEASE

Seventeen unrelated individuals with TBMD were studied. The diagnosis of TBMD was made when a uniformly thinned GBM was present on grid measurements of electron micrographs of the renal biopsies. ${ }^{21}$ All patients had the typical clinical features of TBMD, and none had a family history of Alport syndrome or renal mesangial IgA deposits suggestive of IgA glomerulonephritis, another common renal disease.

Clinical details of patients were recorded and the eyes examined. Visual acuity and any difficulties with night vision were noted. The patients' eyes were then dilated with tropicamide $1 \%$. Ophthalmic examination was performed using a slit-lamp to look at the anterior segment, biomicroscopic fundus examination with a $78 \mathrm{D}$ lens, direct ophthalmoscopy, and fundal photographs. Two patients were investigated further with fluorescein angiography and 

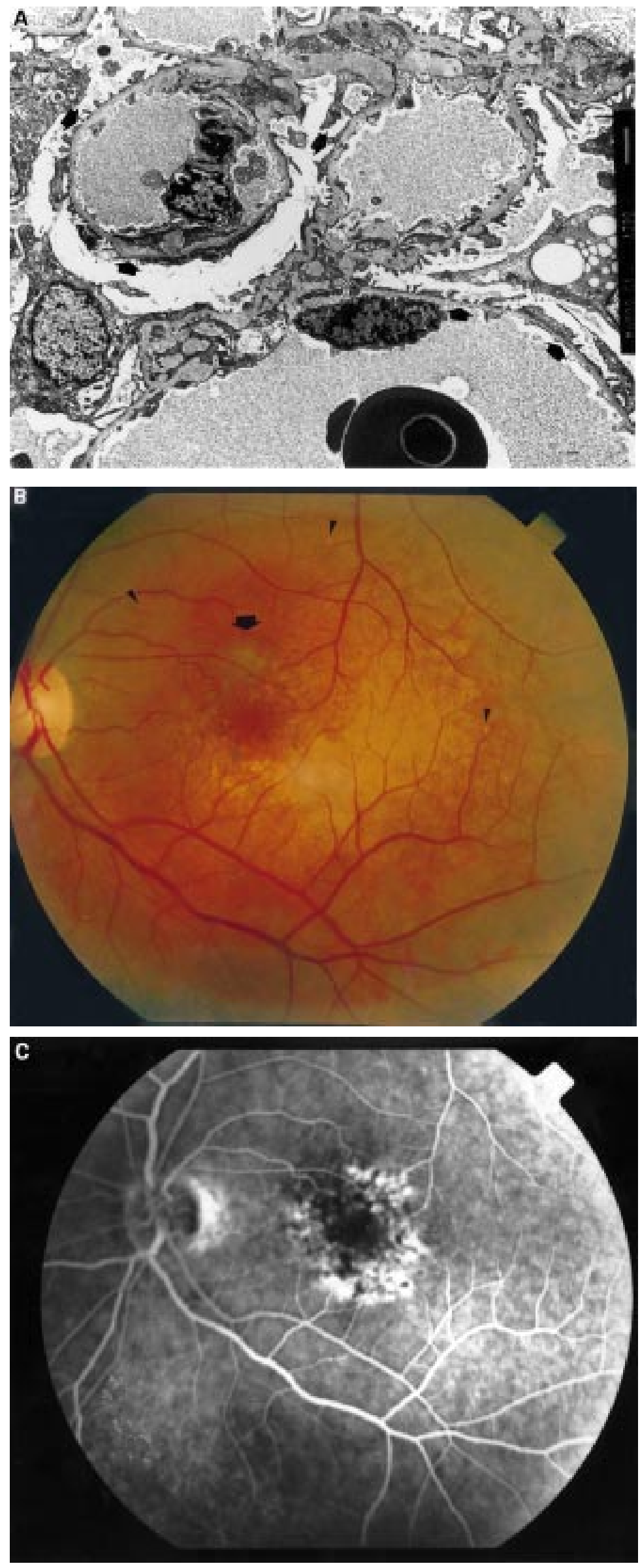

retinal electrophysiological studies. Electroretinography was performed using a Ganzfield stimulus with skin electrodes and a Medelec Sensor machine. The flash stimulus rate was $2 \mathrm{~Hz}$. Dark adaptation was performed after the patient had been placed in the dark, and measured to 20 minutes' duration using a Goldmann-Weekers adaptometer.

IGA GLOMERULONEPHRITIS

Patients with IgA disease were studied as a control group. TBMD is a common disease, and can only be excluded by ultrastructural measurements of the GBM on a renal biopsy. Patients with IgA glomerulonephritis have similar clinical features to those with TBMD, but coincidental TBMD is excluded on biopsy.

The eyes of 11 patients with IgA glomerulonephritis were examined. None had coincidental TBMD.

$\mathrm{X}$ LINKED ALPORT SYNDROME

Ocular findings were also compared with those from patients with X linked Alport syndrome. Six patients from five families were studied. There were three affected males and three carrier females. The diagnosis of Alport syndrome was made when a patient had the typical clinical features, especially in association with a family history of this condition, and when the lamellated GBM characteristic of Alport syndrome was present on electron micrographs.

\section{NORMAL INDIVIDUALS}

Fundal photographs of normal individuals from the Melbourne Visual Impairment Project (VIP) were reviewed $(n=36)$. These were age-matched for the patients with TBMD, but medical histories of these individuals, in particular a history of TBMD, were not known.

Informed consent was obtained from all individuals, and this project was approved by the human ethics committee of the Austin and Repatriation Medical Centre.

STATISTICAL ANALYSIS

The number of retinal dots in patients with TBMD was compared with the age of the patients, the number of glomerular red blood cells (RBC) and the amount of proteinuria, using linear regression analysis; and between patients with and without hypertension using $\chi^{2}$ analysis.

\section{Results}

THIN BASEMENT MEMBRANE DISEASE (TABLE 1)

There were 16 females and one male, with a median age of 48 (range 30-63) years. One individual was deaf but there was no family

Figure 1 (A) Electron micrograph showing diffuse thinning of the glomerular basement membrane (arrows) in a patient with thin basement membrane disease (TBMD) whose optic fundus is shown in $(B)$ and $(C)(\times 1440)$. (B) There is retinal pigment epithelial clumping and maculopathy (thick arrow), and scattered small

yellow-white round dots (small arrows), both close to vessels and in the intervascular spaces in the fundal photograph of the left eye of a patient (IM) with TBMD. (C) Fluorescein angiogram of the fundus of the left eye in the same patient, showing increased fluorescence in the perifoveolar region, but no increased fluorescence of white dots, indicating that these are not small hard drusen. 
Table 1 Renal and ocular features of patients with thin basement membrane disease (TBMD)

\begin{tabular}{|c|c|c|c|c|c|c|c|c|c|}
\hline Patient & $\operatorname{Sex}$ & $\begin{array}{l}\text { Age } \\
\text { (years) }\end{array}$ & $F H$ & Haem & Protein & $B P$ & Cornea & Lens & Retina \\
\hline IM & $\mathrm{F}$ & 49 & - & 180 & 1.6 & + & Pigment & $\mathrm{N}$ & $\begin{array}{l}\text { Retinal pigment } \\
\text { epithelial clumping } \\
\text { maculopathy } 15 \text { dots }\end{array}$ \\
\hline IdS & $\mathrm{F}$ & 63 & - & $>500$ & 0.2 & + & $\begin{array}{l}\text { Arcus, } \\
\text { corneal } \\
\text { dystrophy }\end{array}$ & Cataract & 2 dots \\
\hline $\mathrm{RB}$ & $\mathrm{F}$ & 30 & - & 63 & 0.1 & $\mathrm{~N}$ & $\mathrm{~N}$ & $\mathrm{~N}$ & 7.5 dots \\
\hline $\mathrm{OM}$ & $\mathrm{F}$ & 30 & + & 100 & 1.34 & $\mathrm{~N}$ & Dots & $\mathrm{N}$ & 4 dots \\
\hline $\mathrm{JH}$ & M & 54 & - & $>500$ & 0.5 & + & $\mathrm{N}$ & Dots & 0 dots \\
\hline DC & $\mathrm{F}$ & 37 & - & 10 & 0.86 & $\mathrm{~N}$ & Dots & $\mathrm{N}$ & 3.5 dots \\
\hline $\mathrm{RB}$ & $\mathrm{F}$ & 35 & + & 100 & 0.3 & $\mathrm{~N}$ & $\mathrm{~N}$ & $\mathrm{~N}$ & 8 dots \\
\hline $\mathrm{AM}$ & $\mathrm{F}$ & 51 & - & 100 & 0.2 & $\mathrm{~N}$ & Dots & $\mathrm{N}$ & 3 dots \\
\hline RL & $\mathrm{F}$ & 48 & - & 10 & 0.1 & $\mathrm{~N}$ & $\mathrm{~N}$ & $\mathrm{~N}$ & 4.5 dots \\
\hline GK & $\mathrm{F}$ & 36 & - & 40 & 0.1 & $\mathrm{~N}$ & Dots & Dots & 6 dots \\
\hline ML & $\mathrm{F}$ & 49 & - & 90 & 0.1 & + & Arcus & $\mathrm{N}$ & 5.5 dots \\
\hline RH & $\mathrm{F}$ & 44 & - & 12 & 0.1 & $\mathrm{~N}$ & $\mathrm{~N}$ & Dots & 2 dots \\
\hline $\mathrm{DH}$ & $\mathrm{F}$ & 36 & - & 100 & 0.3 & $\mathrm{~N}$ & $\mathrm{~N}$ & $\mathrm{~N}$ & 8 dots \\
\hline IC & $\mathrm{F}$ & 59 & - & 20 & 0.4 & + & $\begin{array}{l}\text { Dots, } \\
\text { arcus }\end{array}$ & $\mathrm{N}$ & 5.5 dots \\
\hline MB & $\mathrm{F}$ & 60 & + & 48 & 0.1 & $\mathrm{~N}$ & $\mathrm{~N}$ & $\mathrm{~N}$ & 10 dots \\
\hline JK & $\mathrm{F}$ & 52 & + & 74 & 0.3 & $\mathrm{~N}$ & $\begin{array}{l}\text { Corneal } \\
\text { dystrophy }\end{array}$ & $\mathrm{N}$ & 0.5 dots \\
\hline MD & $\mathrm{F}$ & 41 & - & micro & 1.38 & $\mathrm{~N}$ & $\mathrm{~N}$ & $\mathrm{~N}$ & 3 dots \\
\hline
\end{tabular}

$\mathrm{N}=$ normal; $\mathrm{FH}=$ family history of $\mathrm{TBMD} ; \mathrm{Haem}=$ number of $\mathrm{RBC} \times 10^{6} / 1 ;$ micro $=$ microscopic haematuria; proteinuria in $\mathrm{g} / 24$ hours; $\mathrm{BP}+=$ blood pressure greater than $140 / 90 \mathrm{~mm} \mathrm{Hg}$; retinal dot counts are given as mean number per individual (left + right eye $\div 2$ )

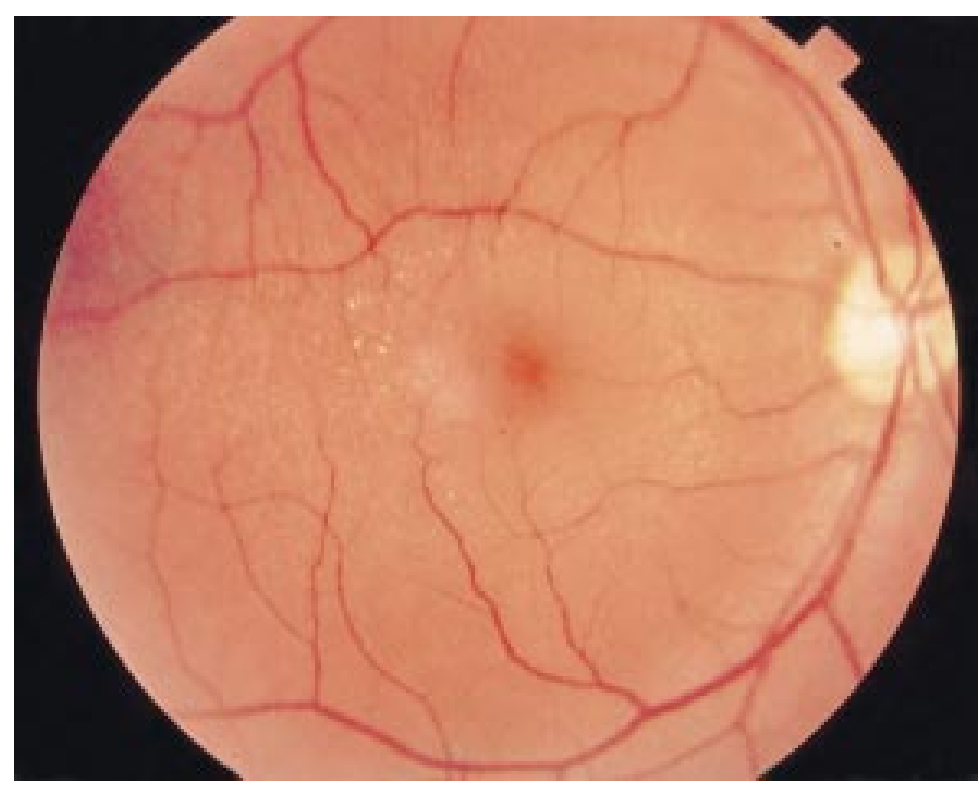

Figure 2 The perifoveal dot and fleck retinopathy in a patient with Xlinked Alport syndrome $(\mathrm{NH})$.
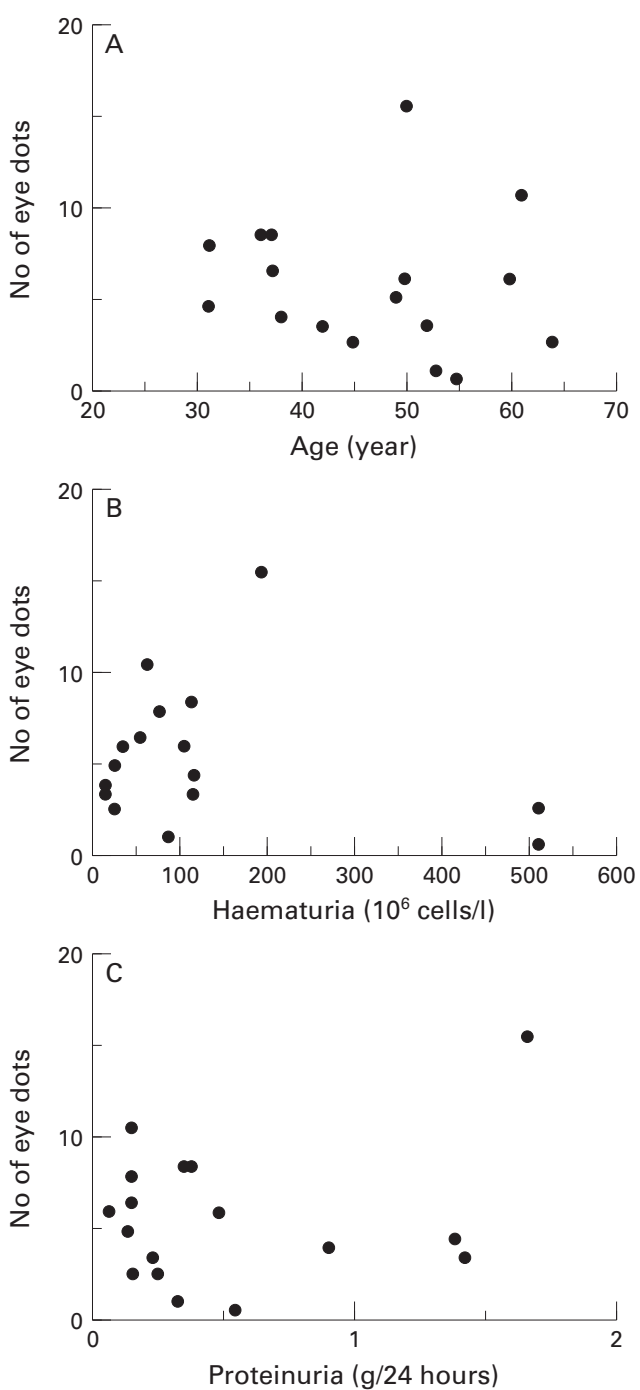

Figure 3 There is no correlation between the average number of retinal dots in any individual and $(A)$ the age of the patients, $(B)$ the number of urinary $R B C \times 10^{6} / l$ at presentation, or $(C)$ the amount of proteinuria at presentation.

blindness. Findings on ocular examination are summarised in Table 1 . No patient had a dot and fleck retinopathy or anterior lenticonus. However, many patients had minor abnormalities affecting the cornea, lens, or retina. Two patients had a corneal dystrophy located at or slightly anterior to Descemet's membrane, one patient had pigmentary changes in the cornea, there was a corneal arcus in three and corneal dots in another five. A cataract was present in the individual with steroid dependent asthma and lens dots were present in three patients. In the retina one patient (IM) had pigment epithelial clumping and a maculopathy (Fig $1(B))$. However, the most common finding was small circumscribed white dots varying in number from none to 30 in both eyes, and located principally in the perimacular area (Fig $1(B))$. Their retinal location was confirmed with contact lens examination, and they were easily distinguished from the dot and fleck retinopathy of Alport syndrome by their smaller size and more regular outline (Fig 2). 
Table 2 Renal and ocular features of patients with IgA glomerulonephritis or Alport syndrome

\begin{tabular}{|c|c|c|c|c|c|c|c|c|c|}
\hline Patient & Sex & Age & Haem & Pro & $B P$ & Renal function & Cornea & Lens & Retina \\
\hline JJ & $\mathrm{F}$ & 37 & + & + & $\mathrm{ABN}$ & $\mathrm{N}$ & $\mathrm{N}$ & $\mathrm{N}$ & 0 dots \\
\hline LJ & $\mathrm{F}$ & 64 & + & + & $\mathrm{N}$ & $\mathrm{N}$ & dots & $\mathrm{N}$ & 0 dots \\
\hline JB & M & 58 & + & + & $\mathrm{N}$ & $\mathrm{ABN}$ & $\mathrm{N}$ & $\mathrm{N}$ & 100 dots \\
\hline $\mathrm{JM}$ & M & 39 & + & + & $\mathrm{N}$ & $\mathrm{N}$ & $\mathrm{N}$ & $\mathrm{N}$ & 0 dots \\
\hline FE & $\mathrm{F}$ & 46 & + & + & $\mathrm{N}$ & $\mathrm{ABN}$ & $\mathrm{N}$ & $\mathrm{N}$ & 0 dots \\
\hline $\mathrm{FD}$ & $\mathrm{F}$ & 38 & - & - & $\mathrm{N}$ & $\mathrm{N}$ & $\mathrm{N}$ & $\mathrm{N}$ & 0 dots \\
\hline $\mathrm{CL}$ & $\mathrm{M}$ & 23 & + & - & $\mathrm{N}$ & $\mathrm{N}$ & $\mathrm{N}$ & $\mathrm{N}$ & 0 dots \\
\hline $\mathrm{HP}$ & $M$ & 51 & + & - & $\mathrm{N}$ & $\mathrm{N}$ & $\mathrm{N}$ & $\mathrm{N}$ & 0 dots \\
\hline TW & M & 51 & + & + & $\mathrm{N}$ & $\mathrm{ABN}$ & $\mathrm{N}$ & $\mathrm{N}$ & 0 dots \\
\hline GJ & $M$ & 44 & + & + & $\mathrm{ABN}$ & $\mathrm{ABN}$ & $\mathrm{N}$ & $\mathrm{N}$ & $1 \mathrm{dot}$ \\
\hline FR & $\mathrm{F}$ & No $f$ & details & & & & $\mathrm{N}$ & $\mathrm{N}$ & 0.5 dots \\
\hline
\end{tabular}

(B) X linked Alport syndrome

\begin{tabular}{|c|c|c|c|c|c|c|c|c|c|}
\hline Patient & Sex & $\begin{array}{l}\text { Age } \\
\text { (years) }\end{array}$ & $F H$ & Hearing & Renal function & $\begin{array}{l}\text { Age at renal } \\
\text { failure }\end{array}$ & Cornea & Lens & Retina \\
\hline $\mathrm{DH}$ & $M$ & 17 & + & Abn & $\mathrm{N}$, haem & NA & $\begin{array}{l}\text { Corneal } \\
\text { dystrophy }\end{array}$ & Dots & $1 \mathrm{dot}$ \\
\hline $\mathrm{PH}^{\star}$ & $\mathrm{F}$ & 45 & + & $\mathrm{N}$ & $\mathrm{N}$, haem & NA & $\begin{array}{l}\text { Corneal } \\
\text { dystrophy }\end{array}$ & $\mathrm{N}$ & $0.5 \mathrm{dot}$ \\
\hline JT & $\mathrm{F}$ & 46 & + & $\mathrm{N}$ & $\mathrm{N}$, haem & NA & $\mathrm{N}$ & Opacity & 6 dots \\
\hline $\mathrm{NH}$ & M & 30 & - & Abn & Transplant & 15 & Dots & $\begin{array}{l}\text { Scissor's } \\
\text { reflex }\end{array}$ & $\begin{array}{l}\text { Dots and } \\
\text { flecks }\end{array}$ \\
\hline $\mathrm{AC}$ & M & 34 & - & Abn & Transplant & 17 & $\mathrm{~N}$ & $\mathrm{~N}$ & $\begin{array}{l}\text { Dots and } \\
\text { flecks }\end{array}$ \\
\hline $\mathrm{CH}$ & $\mathrm{F}$ & 37 & + & $\mathrm{N}$ & $\mathrm{N}$, haem & NA & $\mathrm{N}$ & $\mathrm{N}$ & $1 \mathrm{dot}$ \\
\hline
\end{tabular}

Haem $=+$ RBC greater than $\times 10^{6} / 1$ Pro $=$ proteinuria + more than $0.3 \mathrm{~g} /$ day; $\mathrm{BP}+=$ blood pressure more than $140 / 90 \mathrm{~mm} \mathrm{Hg}$; $\mathrm{FH}=$ family history; $\mathrm{N}=$ normal; $\mathrm{Abn}=$ abnormal; $\mathrm{NA}=$ not applicable.

${ }^{\star} \mathrm{PH}$ and $\mathrm{DH}$ are mother and son; electron microscopy of PH's renal biopsy was typical of Alport syndrome, but DH has not had a biopsy.

Two patients (including IM) underwent fluorescein angiography and electroretinographic studies. On angiography, there was no enhancement of the dots with fluorescein (Fig $1(\mathrm{C})$ ). The electroretinogram in this patient was nearly normal. The scotopic blue amplitudes showed slightly delayed latencies, of 78 $\mathrm{ms}$ in the right eye and 73 in the left (N $59+4$, mean plus $1 \mathrm{SD}$ ), with amplitudes of $42.9 \mathrm{mV}$ in the right eye and 35.7 in the left ( $\mathrm{N} 46+$ 12). The scotopic amplitudes for the B-waves were normal. The photopic red electroretinogram showed slightly delayed latencies, being $37.6 \mathrm{~ms}$ in the right and $36.8 \mathrm{~ms}$ in the left $(\mathrm{N}$ $28+1$ ), and amplitudes were normal at 25.8 in the right and 27.9 in the left. The electrophysiological responses were otherwise normal. The electro-oculogram showed a normal response with Arden index in the right eye of 2.89 and in the left of 3.41. Dark adaptation was normal. The electroretinogram in the other patient was normal.

In the 17 patients with TBMD there was no correlation between the number of retinal dots and the age of the patients, the number of RBC $\times 10^{9} / 1$ of urine, or the amount of proteinuria $\left(r^{2}=0.019,0.36\right.$, and 0.053 respectively) (Fig 3(A), (B), and (C)). The median number of dots in patients with TBMD and hypertension was 5.5 (range 0-15) compared with 5.5 $(2-10)$ in the patients without hypertension ( $p$ NS).

IGA GLOMERULONEPHRITIS (TABLE 2)

Corneal dots were noted in one patient $(9.1 \%)$, and retinal dots in three of the 11 patients $(27 \%)$ with IgA glomerulonephritis.
ALPORT SYNDROME (TABLE 2)

Anterior lenticonus was not seen in any of the six patients with $\mathrm{X}$ linked Alport syndrome. However, a 'scissors reflex' was present in both eyes of one of these patients $(\mathrm{NH})$, resulting in the 'oil droplet' appearance that is associated with anterior lenticonus. Two patients had a dot and fleck retinopathy. In AC, the 'peripapillary sheen' seen on funduscopy was attributed to a dot and fleck retinopathy only when the fundal photographs were subsequently examined. These three patients were all males with renal failure and deafness. There was no impairment of visual acuity or any night blindness associated with the retinopathy.

Corneal abnormalities included superior corneal dystrophy (in mother and son, $\mathrm{PH}$ and $\mathrm{DH}$ ), and corneal white spots. Lens dots and opacity were noted in other patients.

The retinal dots seen in the patients with TBMD were present in all of the patients with $\mathrm{X}$ linked Alport syndrome, who did not have the dot and fleck retinopathy, and the three carrier females with haematuria and normal renal function and hearing. Again there was no associated impairment of visual acuity or night blindness. Dot numbers varied from one to six in each eye.

NORMAL INDIVIDUALS

Retinal dots were present in 31/36 (86\%) normal individuals whose fundal photographs were obtained as part of the Melbourne VIP epidemiological study. The median number of average dots per individual was 1.5 (range 0-34.5). 


\section{Discussion}

We did not observe anterior lenticonus or a dot and fleck retinopathy that are characteristic of Alport syndrome in any patient with TBMD, but ocular abnormalities that were present included corneal dystrophy, arcus and dots, lens cataracts and dots, retinal pigment epithelial clumping and maculopathy, and retinal dots. Most of these lesions have previously been described in patients with X linked Alport syndrome, and in this study they occurred slightly more often in patients with TBMD than in those with a non-genetic renal disease that does not affect the GBM, such as IgA glomerulonephritis. While some of these abnormalities were probably coincidental findings, related to age, or resulting from treatment for other medical conditions, three lesions may have had a common pathogenesis with the thinned GBM of TBMD. These were the corneal dystrophies, the retinal pigment epithelial clumping, and the retinal dots.

A corneal dystrophy was noted in two patients with TBMD. The proximity of this lesion to Descemet's membrane, and the similarity of this structure to the GBM suggested that the dystrophy might occur because of a thinned basement membrane. In addition, we noted a corneal dystrophy in two related individuals with Alport syndrome. These corneal dystrophies, nevertheless, were readily distinguishable from the posterior polymorphous dystrophy that is pathognomonic of Alport syndrome.

Secondly, the retinal pigment epithelial clumping and maculopathy in another patient with TBMD is rarely observed in the normal population. Again the proximity to the choriocapillaris suggested an abnormality of the basement membrane.

Finally, the most common abnormality we noted in patients with TBMD was retinal dots. However, these dots were also present in patients with Alport syndrome, IgA disease, and normal individuals. The number of dots in patients with TBMD did not correlate with any factor reflecting renal damage such as the amount of glomerular haematuria or proteinuria, or the presence of hypertension. The absence of fluorescence and the normal electrophysiological studies suggested that the dots were degenerating retinal pigment epithelial cells, ${ }^{22}{ }^{23}$ which occur when the retina is disrupted by abnormal constituents or an abnormal metabolism. ${ }^{24}$ However, we did not find dots more often in individuals with TBMD than in the normal controls. These dots were easily distinguished from the drusen seen in the dot and fleck retinopathy of Alport syndrome by their small size and sharp demarcation; and the absence of hypertension in most of these patients excluded Elschig's spots. Thus these retinal dots are not characteristic of TBMD and probably do not result from thinning of retinal basement membranes.

The lower frequency of ocular lesions in TBMD than in Alport syndrome may be because the abnormal protein in TBMD is more sparsely distributed in the basement membranes of the eye than of the kidney, or because the abnormal protein is part of a less important structure in the eye than the kidney. Alternatively, the protein may be less affected by the mutations responsible for TBMD.

This work was supported by the National Health and Medical Research Council of Australia. We would like to thank Dr Shirley Sarks for helpful discussions; Professor Hugh Taylor and Shirley Sarks for helpful discussions; Professor Hugh Taylor and
Dr J Stanislavsky of the Melbourne Visual Impairment Project for permission to look at normal retinal survey data; Dr David Mackey, of the Ocular Diagnostic Clinic, Royal Victorian Eye and Ear Hospital for performing the ocular electrophysiology studies; and Roy Larkin of the Medical Photography Department, Austin Hospital, and Glennis Grant, Medical Photography Department, Royal Victorian Eye and Ear Hospital, for their assistance with medical photography.

These data have been presented in part at the Third International Alport Workshop, Erlangen, Germany, September 1994; at the International Congress of Nephrology, Madrid, July 1995; and at the Royal Australian College of Ophthalmologists' Annual Scientific meeting, Melbourne, November 1995.

1 Dische FE, Anderson VER, Keane SJ, Taube D, Beswick M, Parsons V. Incidence of thin membrane nephropathy: morphometric investigation of a population sample. 7 Clin Path 1990;43:457-60.

2 Dische FE, Weston M, Parsons V. Abnormally thin glomerular basement membranes associated with haematuria, proteinuria or renal failure in adults. Am $\mathcal{f}$ Nephrol 1985;5:103-9.

3 Tiebosch ATMG, Frederik PM, van Breda Vriesman PJC, Mooy JMV, van Rie H, van der Wiel TWM, et al. Thin-basement-membrane nephropathy in adults with Thin-basement-membrane nephropathy in adults
persistent hematuria. N Engl f Med 1989;320:14-8.

persistent hematuria. N Engl F Med 1989;320:14-8.
4 Perry G, George CRP, Field MJ, Collett PV, Kalowski S, Wyndham RN, et al. Thin-membrane nephropathy-a common cause of glomerular haematuria. Med f Aust 1989;151:638-42.

5 Rogers PW, Kurtzman NA, Bunn SM, White MG. Familial benign essential hematuria. Arch Intern Med 1973;131: 257-62.

6 Reeders ST. Molecular genetics of hereditary nephritis. Kidney Int 1992;42:783-92.

7 Hill GS, Jenis EH, Goodloe S. The nonspecificity of the ultrastructural alterations in hereditary nephritis. With additional observations on benign familial hematuria. Lab Invest 1974;31:516-32.

8 Barker DF, Hostikka SK, Zhou J, Chow LT, Oliphant AR, Gerken SC, et al. Identification of mutations in the COL4A5 collagen gene in Alport syndrome. Science 1990; 248:1224-7.

9 Atkin CL, Gregory MC, Border WA. Alport syndrome. In: Schrier RW, Gottschalk CW, eds. Diseases of the kidney. Boston: Little Brown, 1988:617-41.

10 Flinter F. Molecular genetics of Alport syndrome. $Q \mathcal{F} \mathrm{Med}$ 1993;86:289-92.

11 Cheong HI, Kashtan CE, Kim Y, Kleppel MM, Michael AF. Immunologic studies of type IV collagen in anterior lens capsules of patients with Alport syndrome. Lab Invest 1994;70:553-7.

12 Ishizaki M, Westerhausen-Larson A, Kino J, Hayashi T, Kao WW-Y. Distribution of collagen IV in human ocular tissues. Invest Ophthalmol Vis Sci 1993;34:2680-9.

13 Iverson UM. Hereditary nephropathy with hearing loss: 'Alport syndrome'. Acta Paediatr Scand 1974;245 (suppl): $-23$.

14 Brownell RD, Wolter JR. Anterior lenticonus in familial haemorrhagic nephritis. Arch Ophthalmol 1964;71:481-3.

15 Govan JAA. Ocular manifestations of Alport's syndrome: a hereditary disorder of basement membranes. Br f Ophthalmol 1983;67:493-503.

16 Perrin D, Jungers P, Grunfeld JP, Delons S, Noel L-H, Zenati C. Perimacular changes in Alport's syndrome. Clin Nephrol 1980;13:163-7.

17 Sabates R, Krachmer SH, Weingeist TA. Ocular findings in Alport's syndrome. Ophthalmologica 1983;186:204-10.

18 Zylbermann R, Silverstone BZ, Brandes E, Drukker A. Renal lesions in Alport's syndrome. 7 Pediatr Ophthalmol Strabismus 1980;17:256-60.

19 Regenbogen LS. Alport syndrome. In: Regenbogen LS, Eliahou HE, eds. Diseases affecting the eye and the kidney. Eliahou HE, eds. Diseases affe

20 Mochizuki T, Lemminck HH, Mariyama M, Antignac C, Gubler M-C, Pirson Y, et al. Identification of mutations in the alpha 3(IV) and alpha 4(IV) collagen genes in autosomal recessive Alport syndrome. Nature Genetics 1994;8:77-82. 21 Jensen EB, Gundersen HJG, Osterby R. Determination of
membrane thickness distribution from orthogonal intercepts. F Microsc 1978;115:19-33.

22 El Baba F, Green WR, Fleischmann J, Finkelstein D, De La Cruz Z. Clinicopathologic correlation of lipidisation and detachment of the retinal pigment epithelium. $A m \mathcal{F}$ Ophthalmol 1986;101:576-83.

23 Fine BS. Lipoidal degeneration of the retinal pigment epithelium. Am f Ophthalmol 1981;91:469-73.

24 Fine BS, Kwapian RP. Pigment epithelial windows and drusen: an animal model. Invest Ophthalmol Vis Sci 1978;17:1059-68. 